\title{
Magnetic sweet graphene nanosheets: preparation, characterization and application in removal of methylene blue
}

\author{
M. Namvari ${ }^{1,2} \cdot$ H. Namazi ${ }^{3,4}$
}

Received: 1 February 2015/Revised: 21 August 2015/Accepted: 2 September 2015/Published online: 6 October 2015

(C) Islamic Azad University (IAU) 2015

\begin{abstract}
Magnetic glucose-functionalized graphene nanosheets (GNS) were prepared, and the application of these biosorbents in the removal of methylene blue was investigated. $\mathrm{Fe}_{3} \mathrm{O}_{4}$ nanoparticles were deposited on sweet GNS using coprecipitation. The nanocomposites were analyzed by Fourier transform infrared spectroscopy, field emission scanning electron microscopy, transition electron microscopy, vibrating sample magnetometer and X-ray diffraction spectrometry. The resulted magnetic sweet GNS were superparamagnetic, responded quickly to an external magnetic field and exhibited efficient adsorption toward methylene blue, as a cationic dye. No leaching was observed even after a week of placing a magnet close to the vial containing the solution of magnetic sweet GNS.
\end{abstract}

Keywords Sweet graphene nanosheets - Click reaction . Magnetic nanoparticles · Methylene blue $\cdot$ Biosorbent

\section{Introduction}

In recent decades, magnetite $\left(\mathrm{Fe}_{3} \mathrm{O}_{4}\right)$ nanoparticles (NPs) have gained global attention in many areas of science particularly as separation tools due to their unique size- and

H. Namazi

namazi@tabrizu.ac.ir

1 Nanshan District Key Lab for Biopolymers and Safety Evaluation, College of Materials Science and Engineering, Shenzhen University, 518060, Shenzhen, China

2 Optoelectronic Engineering Postdoctoral Center, Shenzhen University, 518060, Shenzhen, China

3 Laboratory of Dendrimers and Nano-Biopolymers, Faculty of Chemistry, University of Tabriz, Tabriz, Iran

4 Research Center for Pharmaceutical Nanotechnology (RCPN), Tabriz University of Medical Science, Tabriz, Iran morphology-dependent physical and chemical properties as well as being biocompatible and possessing significant magnetism (Indira and Lakshmi 2010). Despite the advantages, $\mathrm{Fe}_{3} \mathrm{O}_{4}$ NPs tend to aggregate, are sensitive to oxidation and show low dispersibility in aqueous solutions (Yao et al. 2012). To overcome these difficulties, several approaches such as introducing a shell structure including silica (Zhu et al. 2011), polymer (Shin and Jang 2007) and noble metals (Cho et al. 2005; He et al. 2010; Xie et al. 2012) have been studied.

Graphene (Novoselov et al. 2004), a single atom thick of $\mathrm{sp}^{2}$ bonded carbon atoms, possesses a large surface area, flexibility, chemical stability and very high electrical conductivity which makes it a very fascinating material in vast areas of nanoscience and nanotechnology (Zhu et al. 2010). Graphene has proved to be a very suitable substrate for the chemical deposition of many types of NPs (Liu et al. 2013) presenting the outstanding properties of each component, thus resulting in a promising material in various fields. Among all the graphene-based nanocomposites reported to date, graphene $/ \mathrm{Fe}_{3} \mathrm{O}_{4}$ composites (Yang et al. 2009; Shen et al. 2010) or hybrids (Namvari and Namazi 2014c; He et al. 2010; Xie et al. 2012; Zhan et al. 2011) have been attracted a great deal of interest due to their potential applications in enhanced optical limiting, energy storage, magnetic resonance imaging (MRI), drug delivery and environmental remediation (Liu et al. 2013; Li et al. 2011a, b; Zhang et al. 2010; Cong et al. 2010; Namvari and Namazi 2014a, c, 2015). It is worth mentioning that graphene nanosheets (GNS) prevent anchored NPs from agglomeration, while magnetic NPs keep GNS from aggregation. Three methodologies were introduced to prepare magnetic GNS which have their own merits and drawbacks (Indira and Lakshmi 2010). Carbohydrates (Kabiri and Namazi 2014a, b) are known to stabilize $\mathrm{Fe}_{3} \mathrm{O}_{4}$ NPs. Chitosan and carboxymethyl chitosan have shown good results (Zhu et al. 2008). Li et al. (2008) have covalently 
attached $\mathrm{Fe}_{3} \mathrm{O}_{4}$ NPs onto chitosan. Chang et al. (2011) have synthesized magnetic NPs in the presence of soluble starch, carboxymethyl cellulose and agar. FTIR spectra of the samples showed that strong interaction between $\mathrm{Fe}_{3} \mathrm{O}_{4}$ NPs and polysaccharides has controlled the growth of the NPs.

Discharge of dyes to surface and underground water has been of great concern to scientist, and several technologies have been developed in this regard, e.g., biological treatment (Kornaros and Lyberatos 2006), coagulation/flocculation (Guibal and Roussy 2007), ozone treatment (Zhao et al. 2006), chemical oxidation (Dutta et al. 2001), membrane filtration (Capar et al. 2006), ion exchange (Liu et al. 2007), photocatalytic degradation (Muruganandham and Swaminathan 2006) and adsorption (De Lisi et al. 2007). Adsorption, specifically using carbon-based materials, has already drawn considerable attention for the removal of organic dyes because of their high surface area, high stability and abundant functional groups on their surfaces (Chen et al. 2011; Monash and Pugazhenthi 2009; Wang et al. 2011). Graphenic materials are among the most desirable adsorbents among carbonaceous materials (Ramesha et al. 2011; Kui et al. 2012). Introduction of magnetic NPs into graphene will combine the high adsorption capacity of graphene and separation convenience of the magnetic materials which make them very interesting ( $\mathrm{Li}$ et al. 2011a, b). The preparation of magnetic graphene composites and their application in dye removal systems have been reported in the literature (Yao et al. 2012; Xie et al. 2012; Wang et al. 2011; Ai et al. 2011; Geng et al. 2012; Sun et al. 2011).

Herein, we report a novel strategy which can solve the problems associated with the previously reported graphene/ $\mathrm{Fe}_{3} \mathrm{O}_{4}$ composites. Toward this goal, glucose-functionalized GNS via click reaction using two different approaches (Namvari and Namazi 2014b) were used as substrates and deposition of $\mathrm{Fe}_{3} \mathrm{O}_{4}$ NPs was performed using co-precipitation. In this approach, not only magnetic NPs anchor strongly onto hydroxyl groups of glucose moieties which lowers leaching a great deal but also leads to uniform particle size and good dispersion in aqueous media. The resulted magnetic biosorbents showed good efficiency in the removal of methylene blue (MB) from aqueous solutions.

\section{Materials and methods}

\section{Materials}

Graphite (average particle size $30 \mu \mathrm{m}$, Merck, Germany) was used without further purification. Ferrous chloride tetrahydrate $\left(\mathrm{FeCl}_{2} \cdot 4 \mathrm{H}_{2} \mathrm{O}\right)$, ferric chloride hexahydrate $\left(\mathrm{FeCl}_{3} \cdot 6 \mathrm{H}_{2} \mathrm{O}\right)$ and ethanol were used as received without further purification. Methylene blue (MB) was used to prepare stock solutions of $100 \mathrm{mg} \mathrm{L}^{-1}$, which was further diluted to the required concentrations. All the reagents were purchased from Merck, Germany. Deionized water (DI water) was used in all experiments.

\section{Instrumentation}

Infrared spectra were obtained on a Fourier transform infrared (FTIR) spectrometer (model Aquinox 55, Bruker Instruments, Germany) in the $4000-400 \mathrm{~cm}^{-1}$ range at a resolution of $0.5 \mathrm{~cm}^{-1}$ as $\mathrm{KBr}$ pellets. The XRD patterns of all powder samples were recorded on an X-ray diffractometer (D500, Siemens, Germany) using a $\mathrm{Cu} \mathrm{K} \alpha$ $(k=1.54 \mathrm{~A})$ radiation source $(30-40 \mathrm{kV}$ and $40-50 \mathrm{~mA})$ in the range of $2 \theta=4^{\circ}-70^{\circ}$. Room temperature magnetic properties of the composite were characterized using vibrating sample magnetometer [Iran Plasma Nano Colloid (PNC), Model: PNC1k or PNC8K, Iran]. Scanning electron micrographs (SEM) were obtained using a field emission scanning electron microscopy (MIRA3 FEG-SEM, Tescan, Czech Republic) operating at $10 \mathrm{kV}$. Transmission electron micrograph (TEM) was conducted by transmission electron microscope (LEO 906E Carl Zeiss, Germany) operating at $80 \mathrm{kV}$. UV-Vis absorption spectra were recorded on a Shimadzu 1700 Model UV-Vis spectrophotometer (Japan).

\section{Methods}

\section{Preparation of magnetic glucose-functionalized nanocomposites}

The magnetic glucose-functionalized composites were prepared by chemical deposition of iron ions using soluble glucose-modified GO as a substrate. During synthetic process, ideal $\mathrm{Fe}_{3} \mathrm{O}_{4} \mathrm{NPs}$ were obtained under the molar ratio of $\mathrm{Fe}^{3+}: \mathrm{Fe}^{2+}$ as 2:1. 0.5 g rGO-N $\mathrm{N}_{3}$-Glc (Namvari and Namazi 2014b) was first sonicated in $30 \mathrm{~mL}$ diluted $\mathrm{NaOH}$ aqueous solution ( $\mathrm{pH}$ 12) for an hour to transform the hydroxyl groups of glucose moieties to anions, followed by thorough dialysis until the dialysate became neutral. The resulting product was condensed to $20 \mathrm{~mL}$ and placed in a $100-\mathrm{mL}$ three-necked round-bottom flask. A solution of $\mathrm{FeCl}_{3} \cdot 6 \mathrm{H}_{2} \mathrm{O}(0.022 \mathrm{~mol})$ and $\mathrm{FeCl}_{2} \cdot 4 \mathrm{H}_{2} \mathrm{O}(0.011 \mathrm{~mol})$ in water $(20 \mathrm{~mL})$ was added to the flask. The mixture was stirred at $70{ }^{\circ} \mathrm{C}$ for $15 \mathrm{~min}$. Then $2 \mathrm{~mL}$ ammonium hydroxide was added. The mixture was kept stirring at $70{ }^{\circ} \mathrm{C}$ for further $4 \mathrm{~h}$. Then the mixture was washed with water to neutral $\mathrm{pH}$, and $\mathrm{rGO}-\mathrm{N}_{3}-\mathrm{Glc}-\mathrm{Fe}_{3} \mathrm{O}_{4}$ was dried under vacuum at $45{ }^{\circ} \mathrm{C}$ for $12 \mathrm{~h}$. The procedure to the preparation of rGO-diazide-Glc- $-\mathrm{Fe}_{3} \mathrm{O}_{4}$ was the same as mentioned.

\section{Adsorption experiments}

Effects of contact time, solution $\mathrm{pH}$ and the related isotherm were studied individually. Typically, adsorption 
experiments were carried out in glass bottles at $25^{\circ} \mathrm{C}$. Twenty-five milliliters of dye solution of a known initial concentration was shaken with $0.025 \mathrm{~g}$ of magnetic glucose-functionalized GO nanocomposite on a shaker at $200 \mathrm{rpm}$ at $25{ }^{\circ} \mathrm{C}$. To evaluate the time effect, at the completion of preset time intervals, a $5 \mathrm{~mL}$ dispersion was drawn and separated immediately by the aid of a magnet to collect the adsorbent. The equilibrium concentrations of dyes were measured with a UV-Vis spectrophotometer at appropriate wavelength corresponding to the maximum absorbance, $664 \mathrm{~nm}$ for MB. The amount of dye adsorbed was calculated using the following equation:

$q_{\mathrm{e}}=\left(C_{\mathrm{o}}-C_{\mathrm{e}}\right) V / m$

where $q_{\mathrm{e}}$ is the concentration of dye adsorbed $\left(\mathrm{mg} \mathrm{g}^{-1}\right), C_{\mathrm{o}}$ and $C_{\mathrm{e}}$ are the initial and equilibrium concentrations of dye in $\mathrm{mg} \mathrm{L}^{-1}$, respectively, $V$ is the volume of dye solution $(\mathrm{L})$, and $m(\mathrm{~g})$ is the weight of the adsorbent used.

The effect of $\mathrm{pH}$ on the adsorption of MB was studied in a $\mathrm{pH}$ range of $2-10$ using $25 \mathrm{~mL}$ of solutions with $\mathrm{MB}$ concentrations of $20 \mathrm{mg} \mathrm{L}^{-1}$. The initial $\mathrm{pH}$ values of the solutions with certain amount of adsorbent and dye were adjusted with $0.1 \mathrm{M} \mathrm{HNO}_{3}$ or $\mathrm{NaOH}$ using a $\mathrm{pH}$ meter. After magnetic separation using a magnet, the equilibrium concentrations of dyes were measured as mentioned earlier.

For adsorption equilibrium experiments, fixed adsorbent dose $(25 \mathrm{mg})$ was weighed into $50-\mathrm{mL}$ conical flasks containing $25 \mathrm{~mL}$ of different initial concentrations (20-120 $\mathrm{m} \mathrm{L}^{-1}$ ) of MB. The mixture was shaken for $5 \mathrm{~h}$ at $25{ }^{\circ} \mathrm{C}$ until equilibrium was obtained. Then the adsorbent was separated from solution by an external magnet. The concentration of $\mathrm{MB}$ in the solution was measured using a UV-Vis spectrophotometer.

\section{Results and discussion}

We previously reported the synthesis of glucose-functionalized GNS via click reaction (Namvari and Namazi 2014b). Here, the related magnetic composites of the mentioned hydrophilic GNS are prepared, and their structures are illustrated in Scheme 1.

\section{Characterization of the magnetic nanocomposites}

The superparamagnetic behavior of the magnetic composites was verified using an external magnet as shown in Fig. 1. When a magnet was placed close to the vial containing the composites, they readily aggregated to the wall of the vial which proved that the $\mathrm{Fe}_{3} \mathrm{O}_{4}$ NPs have successfully and strongly deposited on the glucose-functionalized GNS and made them magnetically responsive.

The FTIR spectra of glucose-grafted GNS and the related magnetic composites are shown in Fig. 2. The $-\mathrm{C}-$ O- stretching peaks of sweet GNS, which are seen at $1000-1200 \mathrm{~cm}^{-1}$, shifted to lower wavenumbers (1021 and $1033 \mathrm{~cm}^{-1}$, respectively) in the presence of $\mathrm{Fe}_{3} \mathrm{O}_{4}$, indicating that an interaction existed between the GNS and $\mathrm{Fe}_{3} \mathrm{O}_{4}$ (Chang et al. 2011). Besides, the signals assigned to $\mathrm{O}-\mathrm{H}$ of glucose moieties at $3000-3500 \mathrm{~cm}^{-1}$ have shifted (3311 and $3428 \mathrm{~cm}^{-1}$, respectively) and reduced in intensity due to the interaction with magnetic NPs as expected. The characteristic peaks of $\mathrm{Fe}_{3} \mathrm{O}_{4}$ are observed at 573 and $561 \mathrm{~cm}^{-1}$ at the spectra of rGO-N $\mathrm{N}_{3}-\mathrm{Glc}-\mathrm{Fe}_{3} \mathrm{O}_{4}$ and rGOdiazide-Glc- $\mathrm{Fe}_{3} \mathrm{O}_{4}$, respectively. These observations indicated that $\mathrm{Fe}_{3} \mathrm{O}_{4}$ NPs were stabilized by glucose moieties.

The XRD diffraction patterns of rGO-N $3-\mathrm{Glc}_{3}-\mathrm{Fe}_{3} \mathrm{O}_{4}$ and rGO-diazide-Glc- $\mathrm{Fe}_{3} \mathrm{O}_{4}$ are shown in Fig. 3. For rGO-N $3_{3}-$ Glc- $\mathrm{Fe}_{3} \mathrm{O}_{4}$ composite, characteristic peaks are observed at

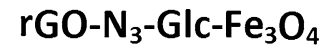

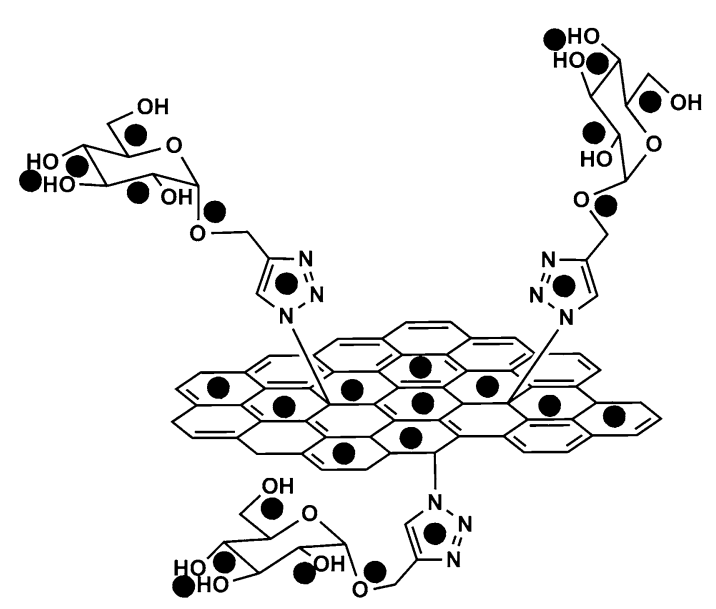

- $\mathrm{Fe}_{3} \mathrm{O}_{4} \mathrm{NPs}$

\section{rGO-diazide-GIc- $\mathrm{Fe}_{3} \mathrm{O}_{4}$}

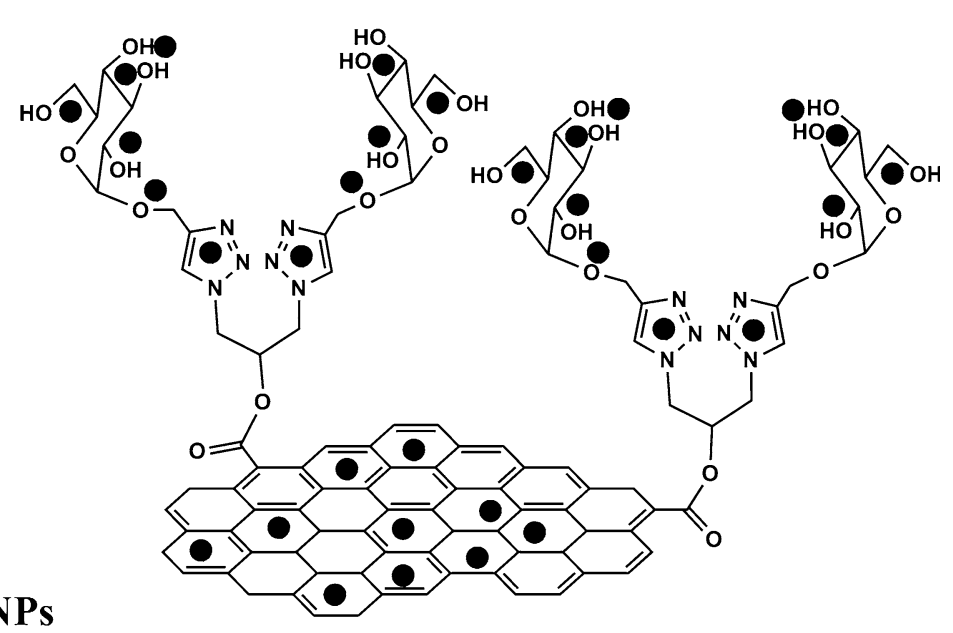

Scheme 1 Magnetic composites of glucose-functionalized GNS 

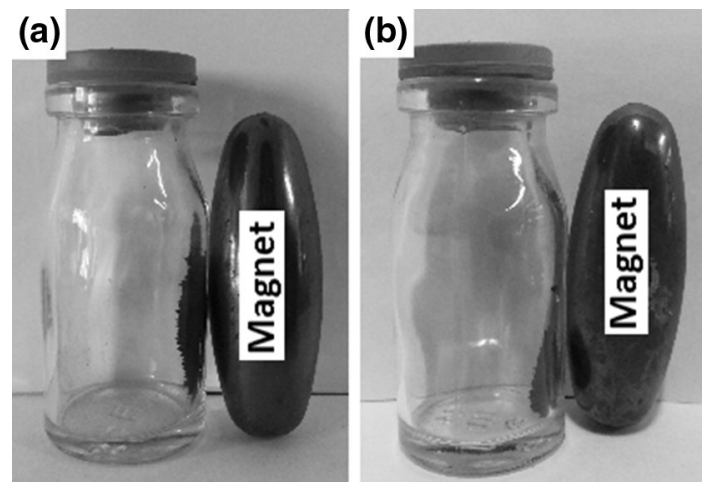

Fig. 1 Image of response of $\mathrm{rGO}-\mathrm{N}_{3}-\mathrm{Glc}_{-}-\mathrm{Fe}_{3} \mathrm{O}_{4}$ (a) and $\mathrm{rGO}$ diazide-Glc- $\mathrm{Fe}_{3} \mathrm{O}_{4}$ (b) to an external magnetic field

$2 \theta$ values of $30.21^{\circ}(220), 35.96^{\circ}(311), 43.83^{\circ}$ (4 00$)$, $53.42^{\circ}(422), 57.53^{\circ}(511)$ and $62.22^{\circ}(440)$ and for rGOdiazide-Glc- $\mathrm{Fe}_{3} \mathrm{O}_{4}$ at $2 \theta$ values of $30.86^{\circ}(220), 34.91^{\circ}(31$ $1), 43.94^{\circ}(400), 53.42^{\circ}(422), 57.21^{\circ}(511)$ and $62.90^{\circ}(44$ $0)$. These results suggest that the particles can be easily indexed to $\mathrm{Fe}_{3} \mathrm{O}_{4}$, plus no obvious diffraction peak corresponding to glucose-grafted GNS is present, indicating that GNS has been almost completely exfoliated and less agglomerated GNS are presented in the composite. The mean diameters of $\mathrm{Fe}_{3} \mathrm{O}_{4}$ crystallites in rGO-N ${ }_{3}-\mathrm{Glc}_{-}-\mathrm{Fe}_{3} \mathrm{O}_{4}$ and GO-diazide-Glc- $\mathrm{Fe}_{3} \mathrm{O}_{4}$ are also estimated using Scherrer's equation to be 14 and $17 \mathrm{~nm}$, respectively, which are in good agreement with the values obtained from TEM and SEM.

FESEM images of the surface of $\mathrm{rGO}-\mathrm{N}_{3}-\mathrm{Glc}_{-} \mathrm{Fe}_{3} \mathrm{O}_{4}(\mathrm{a}, \mathrm{b})$ and rGO-diazide-Glc- $\mathrm{Fe}_{3} \mathrm{O}_{4}$ (c, d) shown in Fig. 4 demonstrate that the prepared magnetic NPs were spherical, narrowly distributed, well dispersed on the basal planes of GNS and firmly anchored on the GNS with high density. It can be

(a)

$\mathrm{rGO}-\mathrm{N}_{3}-\mathrm{GlC}$

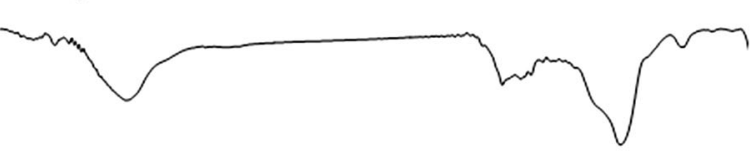

rGO- $\mathrm{N}_{3}-\mathrm{GlC}^{-}-\mathrm{Fe}_{3} \mathrm{O}_{4}$

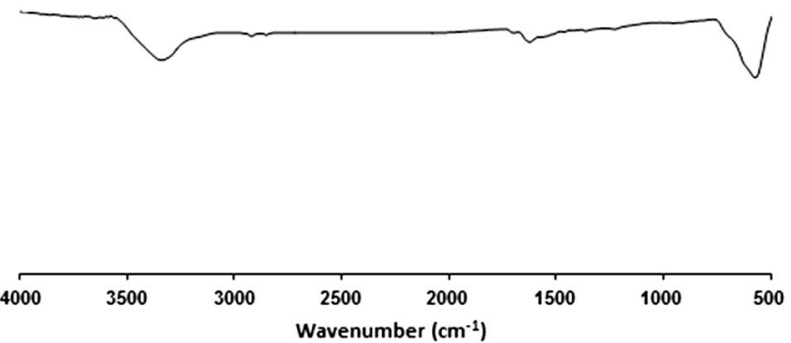

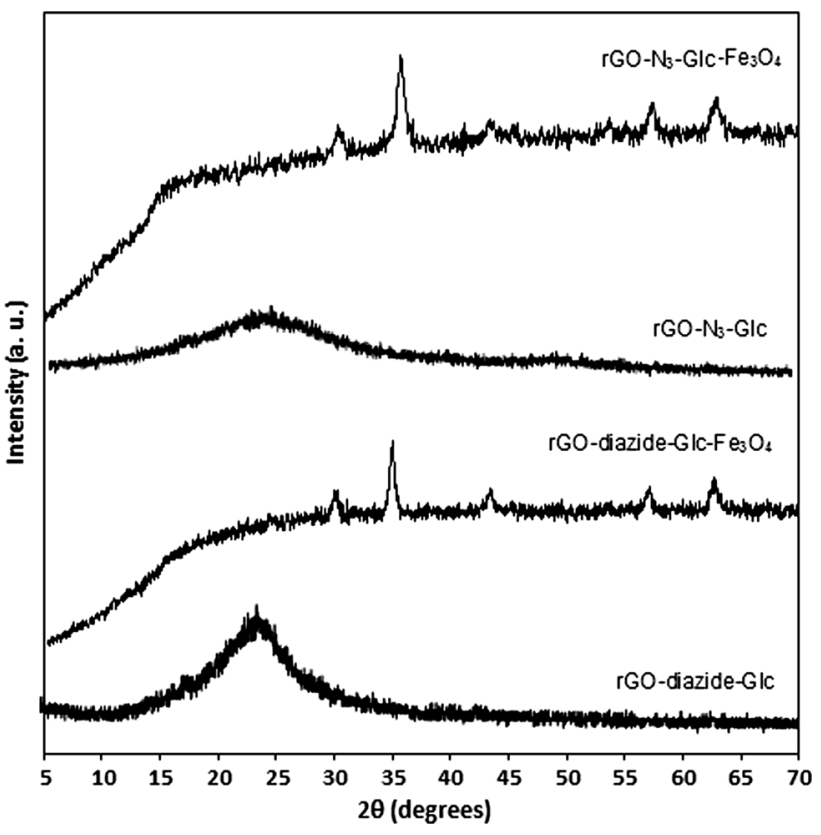

Fig. 3 XRD patterns of rGO-N $\mathrm{N}_{3}-\mathrm{Glc}-\mathrm{Fe}_{3} \mathrm{O}_{4}$ and rGO-diazide-Glc$\mathrm{Fe}_{3} \mathrm{O}_{4}$

observed that the graphene sheets are distributed between the loosely packed $\mathrm{Fe}_{3} \mathrm{O}_{4} \mathrm{NP}$ and the nanoporous composites with void spaces are formed. Notably, functionalized graphene sheets may favor to hinder the $\mathrm{Fe}_{3} \mathrm{O}_{4}$ spheres from agglomeration and enable their good distribution on the sheets, while the $\mathrm{Fe}_{3} \mathrm{O}_{4}$ spheres serve as a stabilizer that separate GNS against the aggregation. This can be of great benefit to modification of GO sheets with carbohydrates.

The TEM images of the composites (Fig. 5) revealed the morphology features. It can be seen that the agglomeration of $\mathrm{Fe}_{3} \mathrm{O}_{4} \mathrm{NP}$ was prevented by the dispersion of $\mathrm{Fe}_{3} \mathrm{O}_{4}$ on

(b)
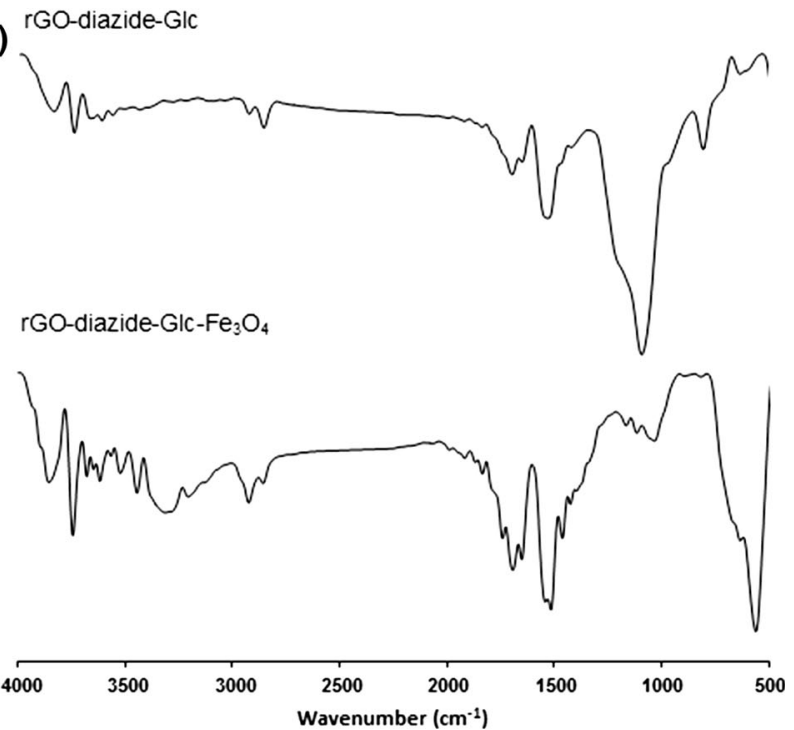

Fig. 2 The FTIR spectra of glucose-grafted GNS and the related magnetic nanocomposites 

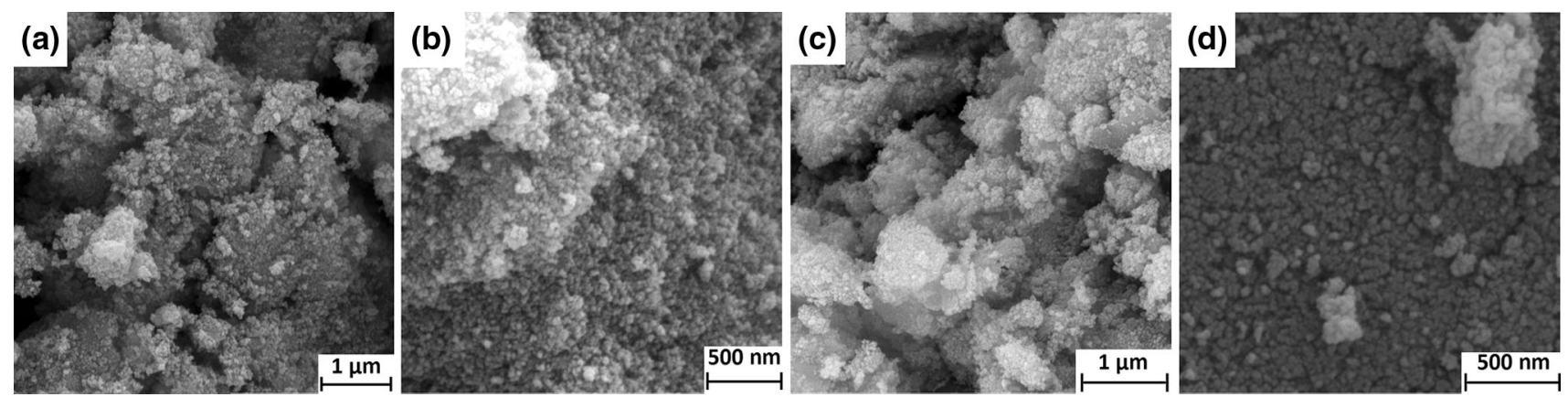

Fig. 4 FESEM images of rGO-N ${ }_{3}-\mathrm{Glc}_{-} \mathrm{Fe}_{3} \mathrm{O}_{4}(\mathbf{a}, \mathbf{b})$ and rGO-diazide-Glc- $\mathrm{Fe}_{3} \mathrm{O}_{4}(\mathbf{c}, \mathbf{d})$

Fig. 5 TEM images of rGO$\mathrm{N}_{3}-\mathrm{Glc}-\mathrm{Fe}_{3} \mathrm{O}_{4}$ (a) and rGOdiazide-Glc- $\mathrm{Fe}_{3} \mathrm{O}_{4}(\mathbf{b})$
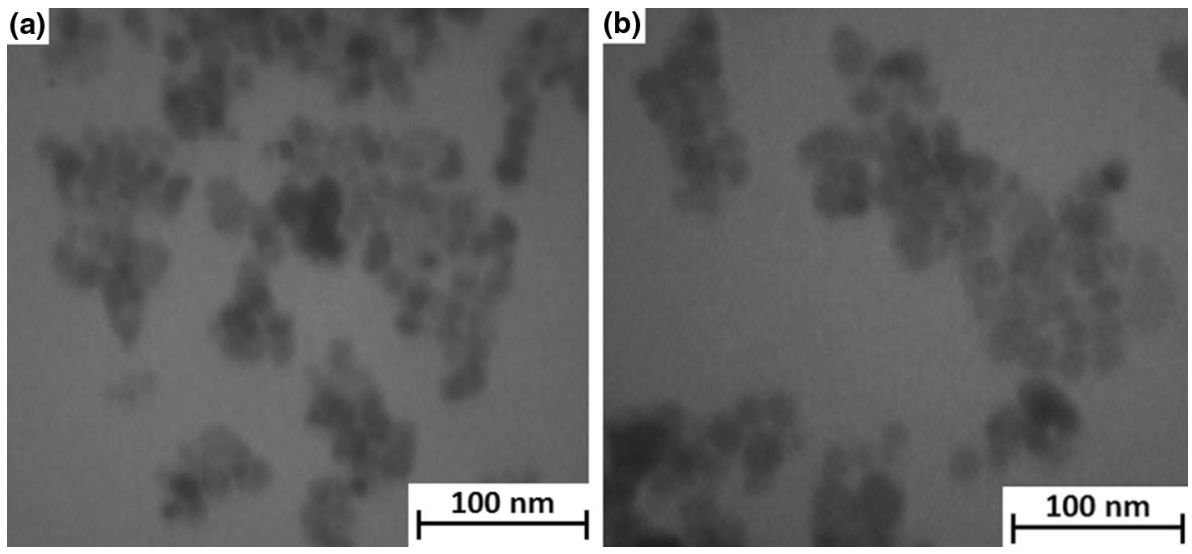

glucose-grafted graphene. Furthermore, carbohydrates could form hybrids with metal ions due to their high number of coordinating functional groups; therefore, nucleation and initial crystal growth of the NPs may have occurred preferentially on glucose moieties (Chang et al. 2011). The average particle size of the iron oxide NPs was determined to be $15 \mathrm{~nm}$ in $\mathrm{rGO}-\mathrm{N}_{3}-\mathrm{Glc}_{-}-\mathrm{Fe}_{3} \mathrm{O}_{4}$ and $19 \mathrm{~nm}$ in GO-diazide-Glc- $\mathrm{Fe}_{3} \mathrm{O}_{4}$ which are consistent with the average particle size calculated from the Scherrer's relation in X-ray diffraction patterns (14 and $17 \mathrm{~nm}$, respectively).

Figure 6 shows the magnetization of sweet GNS as a function of the magnetic field at $25^{\circ} \mathrm{C}$. Their magnetization increased with an increase in the magnetic field. Moreover, the magnetic hysteresis loops are S-like curves and have no coercivity and remanence, implying that there is no remaining magnetization when the external magnetic field is removed. These results indicate that the magnetic composites exhibit typical superparamagnetic behavior, and the single-domain magnetite NPs remained in the composite (Chang et al. 2011). The VSM plots present values of 44.2 and $33.8 \mathrm{emu}^{-1}$ for the saturation magnetization $\left(\mathrm{M}_{\mathrm{s}}\right)$ of rGO-N ${ }_{3}-\mathrm{Glc}_{-}-\mathrm{Fe}_{3} \mathrm{O}_{4}$ (a) and rGO-diazide-Glc- $-\mathrm{Fe}_{3} \mathrm{O}_{4}$ (b), respectively. The obtained results are much lower than that of the bare $\mathrm{Fe}_{3} \mathrm{O}_{4}$ particles reported in the previous literature (Hong et al. 2009). Lower $\mathrm{M}_{\mathrm{s}}$ can be due to the smaller size of the iron oxide NPs and also the contribution of the nonmagnetic graphene layers (Ai et al. 2011).
The leaching of the solution of the magnetic sweet GNS was studied as well. Specific amount of the composites were sonicated in water for $2 \mathrm{~min}$. An external magnetic field was placed close to the vial. The composites quickly aggregated to the wall of the vial. They were observed over a month, and they kept aggregated, and no leaching was observed, indicating that $\mathrm{Fe}_{3} \mathrm{O}_{4}$ NPs were strongly attached to the GNS due to the presence of glucose moieties.

\section{Adsorption studies}

Efficient magnetic response of the prepared composites and the importance of water contamination are the main reasons we decided to study the application of the composites in the removal of $\mathrm{MB}$, as a typical cationic dye, from aqueous solutions. The effect of contact time on the amount of dye adsorbed was investigated at an initial dye concentration of $20 \mathrm{mg} \mathrm{L}^{-1}$ (Fig. 7a). It took $30 \mathrm{~min}$ for $\mathrm{rGO}-\mathrm{N}_{3}-\mathrm{Glc}-\mathrm{Fe}_{3} \mathrm{O}_{4}$ (a) and rGO-diazide-Glc- $\mathrm{Fe}_{3} \mathrm{O}_{4}$ (b) to reach equilibrium. The short equilibrium time needed indicates that the hybrid has high adsorption efficiency to remove cationic dyes from contaminated water. In our previous reports, it took $20 \mathrm{~min}$ for $\mathrm{Fe}_{3} \mathrm{O}_{4}$-clicked GO (Namvari and Namazi 2014a) and $30 \mathrm{~min}$ for GO-CA-Fe $\mathrm{O}_{4}$ (Namvari and Namazi 2014c) to reach equilibrium in the adsorption of $\mathrm{MB}$. Our obtained results are comparable with the ones reported previously (Yao et al. 2012; Xie et al. 2012). 
(a)

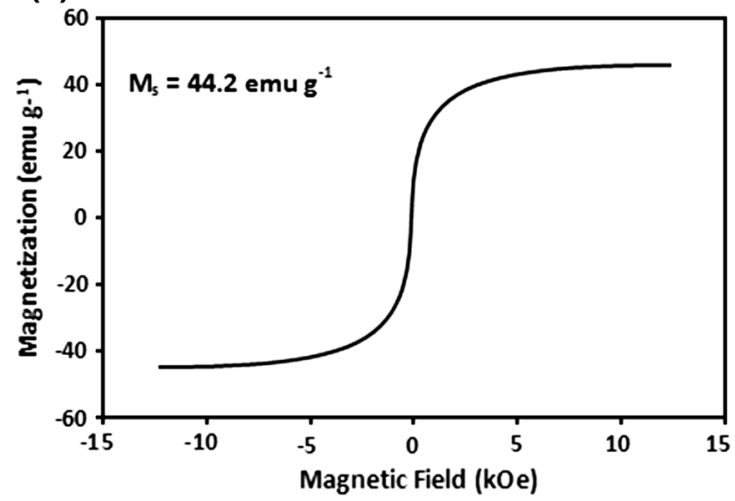

(b)

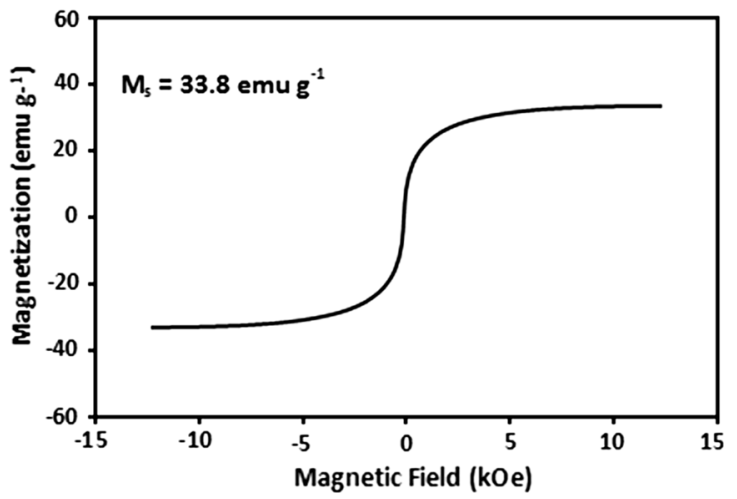

Fig. 6 Magnetization curves obtained by VSM at room temperature of rGO-N $-\mathrm{Glc}_{3}-\mathrm{Fe}_{3} \mathrm{O}_{4}(\mathbf{a})$ and $\mathrm{rGO}-$ diazide-Glc-Fe $\mathrm{O}_{4}(\mathbf{b})$

(a)

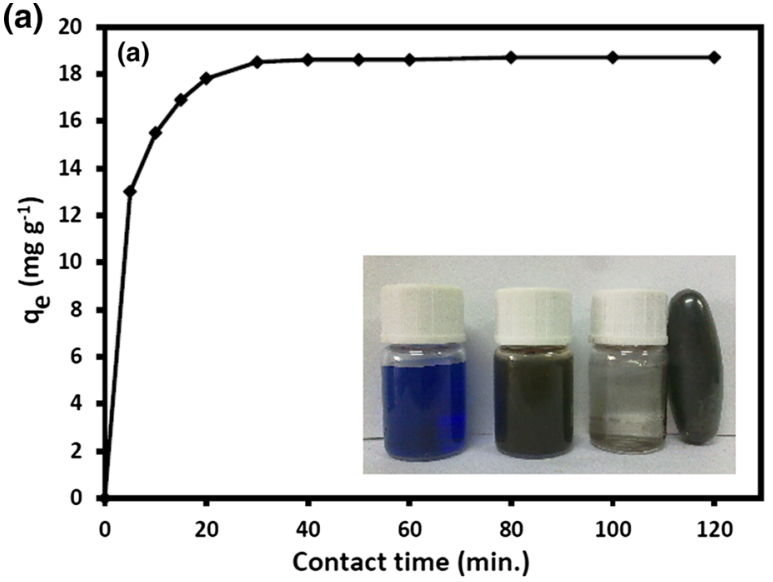

(b)

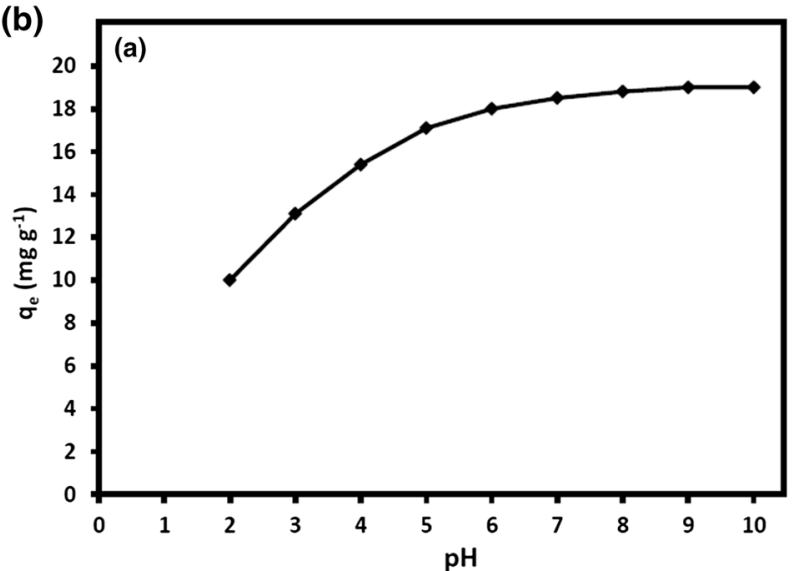

Fig. 7 a The effect of contact time on the adsorption of MB onto rGO$\mathrm{N}_{3}-\mathrm{Glc}_{-} \mathrm{Fe}_{3} \mathrm{O}_{4}(a)$ and $\mathrm{rGO}$-diazide-Glc- $\mathrm{Fe}_{3} \mathrm{O}_{4}(b)$. Insets show photos of magnetic nanocomposites: initial solution of dye (left), solution of the adsorbent and dye (middle) and the response of the solution of the

The effect of $\mathrm{pH}$ on the adsorption of $\mathrm{MB}$ was investigated over the range of $\mathrm{pH}$ values from 2 to 10 (Fig. $7 \mathrm{~b}$ ). Capacity and the rate of adsorption were low in lower $\mathrm{pH}$ values, but enhanced as the $\mathrm{pH}$ increased due to the ionization of glucose moieties. The rate of adsorption increased
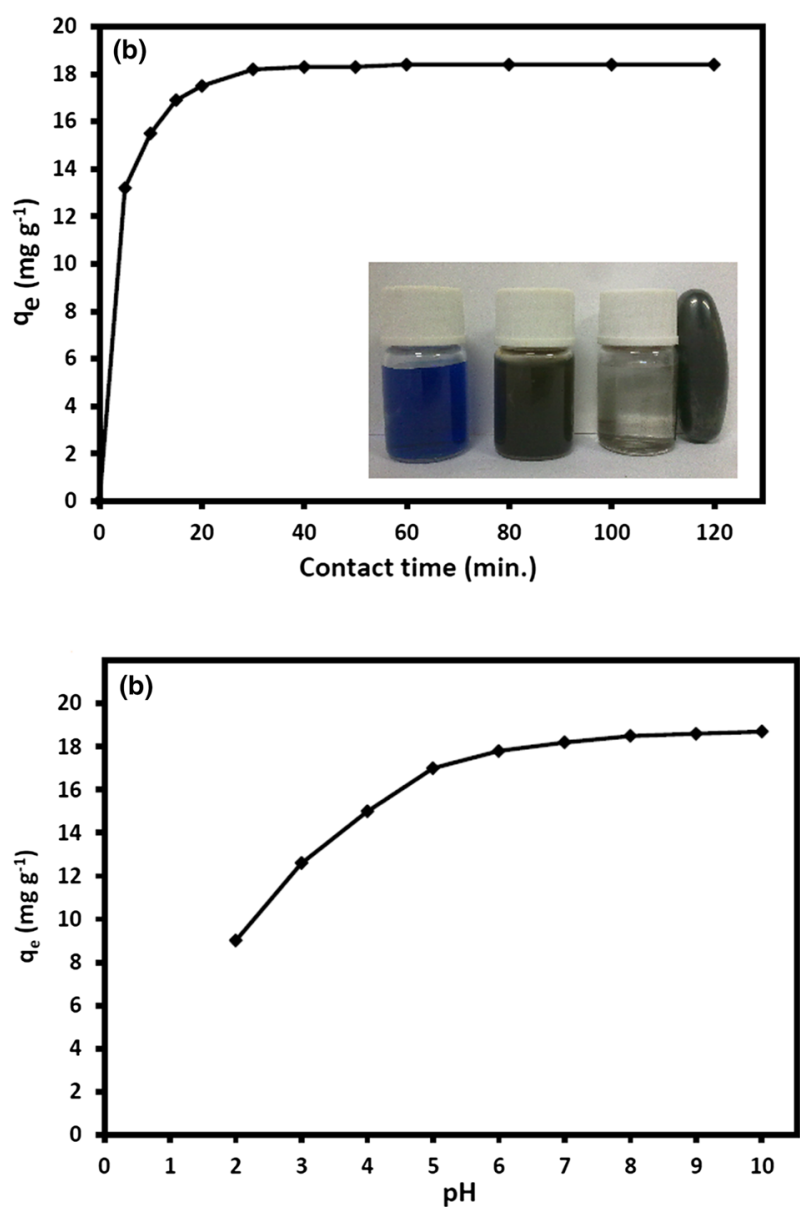

adsorbent and dye to a magnet (right). $\mathbf{b}$ The effect of $\mathrm{pH}$ on the adsorption of $\mathrm{MB}$ onto rGO-N ${ }_{3}-\mathrm{Glc}_{-} \mathrm{Fe}_{3} \mathrm{O}_{4}(a)$ and rGO-diazide-Glc$\mathrm{Fe}_{3} \mathrm{O}_{4}(b)$, (experimental conditions: temperature: $25{ }^{\circ} \mathrm{C}$, adsorbent dose: $25 \mathrm{mg} / 25 \mathrm{~mL}$, initial concentration of dye: $20 \mathrm{mg} \mathrm{L}^{-1}$ )

rapidly up to $\mathrm{pH} 7$, but no significant change was observed afterward. $\mathrm{pH}$ influences surface charge of adsorbent, ionization degree of adsorbate and dissociation of the functional groups on the active sites. Even though hydroxyl groups of glucose moieties are involved with the $\mathrm{Fe}_{3} \mathrm{O}_{4} \mathrm{NPs}$, in higher 

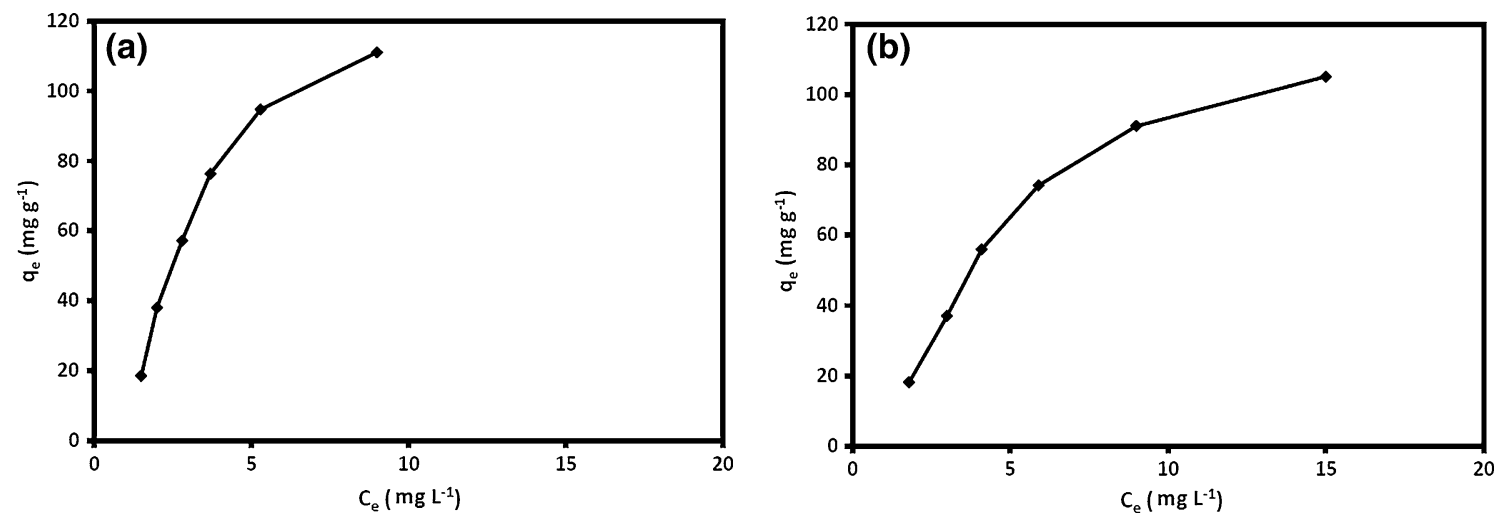

Fig. 8 Adsorption isotherm of $\mathrm{MB}$ onto rGO-N${ }_{3}-\mathrm{Glc}-\mathrm{Fe}_{3} \mathrm{O}_{4}$ (a) and rGO-diazide-Glc- $\mathrm{Fe}_{3} \mathrm{O}_{4}(\mathbf{b})$, (experimental conditions: temperature: $25{ }^{\circ} \mathrm{C}$, adsorbent dose: $25 \mathrm{mg} / 25 \mathrm{~mL}$, concentration of dye: $20-120 \mathrm{mg} \mathrm{L}^{-1}$ )

Table 1 Maximum adsorption capacities for the adsorption of MB onto various adsorbents

\begin{tabular}{|c|c|c|}
\hline Adsorbent & $\begin{array}{l}\text { Maximum } \\
\text { adsorption } \\
\text { capacity } \\
\left(\mathrm{mg} \mathrm{g}^{-1}\right)\end{array}$ & References \\
\hline GO- $\mathrm{Fe}_{3} \mathrm{O}_{4}$ hybrid & 167.2 & Xie et al. (2012) \\
\hline Activated carbon & 521 & Juang et al. (2000) \\
\hline MWCNTs with $\mathrm{Fe}_{2} \mathrm{O}_{3}$ & 42.3 & Qu et al. (2008) \\
\hline $\mathrm{GNS} / \mathrm{Fe}_{3} \mathrm{O}_{4}$ composite & 35.73 & Ai et al. (2011) \\
\hline $\mathrm{TiO}_{2}-\mathrm{GNs}$ & 83.3 & Thuy-Duong et al. (2012) \\
\hline CNT-GNs & 81.97 & Ai and Jiang (2012) \\
\hline $\mathrm{Fe}_{3} \mathrm{O}_{4}$-clicked GO & 98.8 & Namvari and Namazi (2014a) \\
\hline $\mathrm{CA}-\mathrm{GO}-\mathrm{Fe}_{3} \mathrm{O}_{4}$ & 112 & Namvari and Namazi (2014c) \\
\hline $\mathrm{rGO}-\mathrm{N}_{3}-\mathrm{Glc}-\mathrm{Fe}_{3} \mathrm{O}_{4}$ & 111 & The present work \\
\hline rGO-diazide-Glc- $\mathrm{Fe}_{3} \mathrm{O}_{4}$ & 105 & The present work \\
\hline
\end{tabular}

$\mathrm{pHs}$, their dissociation and electrostatic interaction leads to an increase in the adsorption of MB. A decrease in adsorption in low $\mathrm{pH}$ can be due to the protons competition with the dye molecules for the available adsorption sites (Namvari and Namazi 2014c). The obtained results are in good agreement with the adsorption of MB by GO (Yang et al. 2011) and $\mathrm{GNS} / \mathrm{Fe}_{3} \mathrm{O}_{4}$ (Ai et al. 2011).

The adsorption isotherms of MB onto the magnetic composites are shown in Fig. 8. The maximum adsorption capacities at the dye concentration range of $20-120 \mathrm{mg} \mathrm{g}^{-1}$ were attained

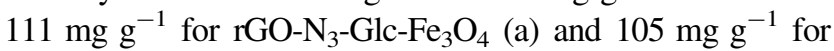
rGO-diazide-Glc- $\mathrm{Fe}_{3} \mathrm{O}_{4}$ (b). To compare the efficiency of the synthesized magnetic composites, maximum capacities of the previously reported adsorbents are given in Table 1.

\section{Conclusion}

In this work, magnetic composite of two types of sweet GNS was prepared. The attachment of $\mathrm{Fe}_{3} \mathrm{O}_{4}$ NPs onto the sweet GNS was confirmed by FTIR, FESEM, XRD and TEM.
Moreover, the magnetic composites show excellent superparamagnetic properties, which help in the separation of the hybrid materials. The presence of glucose moieties on graphene sheets has not only led to the strong attachment of $\mathrm{Fe}_{3} \mathrm{O}_{4}$ onto the GNS but also made these magnetic nanohybrids efficient adsorbents for the removal of cationic dyes such as MB. The maximum adsorption capacities were obtained $111 \mathrm{mg} \mathrm{g}^{-1}$ for rGO- $\mathrm{N}_{3}-\mathrm{Glc}_{-} \mathrm{Fe}_{3} \mathrm{O}_{4}$ and $105 \mathrm{mg} \mathrm{g}^{-1}$ for rGO-diazide-Glc$\mathrm{Fe}_{3} \mathrm{O}_{4}$. High adsorption capacity accompanied by the ease of separation by an external magnetic field makes the prepared magnetic biosorbents ideal candidates for removing organic dyes from polluted water.

Acknowledgments Authors are pleased to acknowledge the University of Tabriz (Grant Number S/27/3243-29) and Research Center for Pharmaceutical Nanotechnology (RCPN), Tabriz University of Medical Science, for financial support of this work. The authors would like to thank the Nanshan District Key Lab for Biopolymers and Safety Evaluation (No.KC2014ZDZJ0001A).

\section{References}

Ai L, Jiang J (2012) Removal of methylene blue from aqueous solution with self-assembled cylindrical graphene-carbon nanotube hybrid. Chem Eng J 192:156-163

Ai L, Zhang C, Chen Z (2011) Removal of methylene blue from aqueous solution by a solvothermal-synthesized graphene/magnetite composite. J Hazard Mater 192:1515-1524

Capar G, Yetis U, Yilmaz L (2006) Membrane based strategies for the pre-treatment of acid dye bath wastewaters. J Hazard Mater 135:423-430

Chang PR, Yua J, Maa X, Anderson DP (2011) Polysaccharides as stabilizers for the synthesis of magnetic nanoparticles. Carbohyd Polym 83:640-644

Chen P, Liang H-W, Lv X-H, Zhu H-Z, Yao H-B, Yu S-H (2011) Carbonaceous nanofiber membrane functionalized by $\beta$-cyclodextrins for molecular filtration. ACS Nano 5:5928-5935

Cho SJ, Idrobo JC, Olamit J, Liu K, Browning ND, Kauzlarich SM (2005) Growth mechanisms and oxidation resistance of gold coated iron nanoparticles. Chem Mater 17:3181-3186

Cong H-P, He J-J, Lu Y, Yu S-H (2010) Water-soluble magneticfunctionalized reduced graphene oxide sheets: in situ synthesis and magnetic resonance imaging applications. Small 6:169-173 
De Lisi R, Lazzara G, Milioto S, Muratore N (2007) Adsorption of a dye on clay and sand: use of cyclodextrins as solubilityenhancement agents. Chemosphere 69:1703-1712

Dutta K, Mukhopadhyaya S, Bhattacharjee S, Chaudhuri B (2001) Chemical oxidation of methylene blue using a Fenton-like reaction. J Hazard Mater 84:57-61

Geng Z, Lin Y, Yu X, Shen Q, Ma L, Li Z, Pan N, Wang X (2012) Highly efficient dye adsorption and removal: a functional hybrid of reduced graphene oxide- $\mathrm{Fe}_{3} \mathrm{O}_{4}$ nanoparticles as an easily regenerative adsorbent. J Mater Chem 22:3527-3535

Guibal E, Roussy J (2007) Coagulation and flocculation of dyecontaining solutions using a biopolymer (Chitosan). React Funct Polym 67:33-42

He F, Fan J, Ma D, Zhang L, Leung C, Chan HL (2010) The attachment of $\mathrm{Fe}_{3} \mathrm{O}_{4}$ nanoparticles to graphene oxide by covalent bonding. Carbon 48:3139-3144

Hong RY, Feng B, Liua G, Wang S, Li HZ, Ding JM, Zheng Y, Wei DG (2009) Preparation and characterization of $\mathrm{Fe}_{3} \mathrm{O}_{4} /$ polystyrene composite particles via inverse emulsion polymerization. J Alloys Compd 476:612-618

Indira TK, Lakshmi PK (2010) Magnetic nanoparticles-a review. Int J Pharm Sci Nanotech 3:1035-1042

Juang RS, Wu FC, Tseng RL (2000) Mechanism of adsorption of dyes and phenols from water using activated carbons prepared from plum kernels. J Colloid Interface Sci 227:437-444

Kabiri R, Namazi H (2014a) Nanocrystalline cellulose acetate (NCCA)/graphene oxide (GO) nanocomposites with enhanced mechanical properties and barrier against water vapor. Cellulose 21:3527-3539

Kabiri R, Namazi H (2014b) Surface grafting of reduced graphene oxide using nanocrystalline cellulose via click reaction. J Nanopart Res 16:2474-2478

Kornaros M, Lyberatos G (2006) Biological treatment of wastewaters from a dye manufacturing company using a trickling filter. J Hazard Mater 136:95-102

Kui L, Xia ZG, Ke WX (2012) A brief review of graphene-based material synthesis and its application in environmental pollution management. Chin Sci Bull 57:1223-1234

Li GY, Jiang YR, Huang KL, Ding P, Chen J (2008) Preparation and properties of magnetic $\mathrm{Fe}_{3} \mathrm{O}_{4}$-chitosan nanoparticle. J Alloys Compd 466:451-456

Li B, Cao H, Shao J, Qu M, Warner JH (2011a) Superparamagnetic $\mathrm{Fe}_{3} \mathrm{O}_{4}$ nanocrystals@graphene composites for energy storage devices. J Mater Chem 21:5069-5075

Li Y, Chua J, Qib J, Li X (2011b) An easy and novel approach for the decoration of graphene oxide by $\mathrm{Fe}_{3} \mathrm{O}_{4}$ nanoparticles. Appl Surf Sci 257:6059-6062

Liu CH, Wu JS, Chiu HS, Suen SY, Chu KH (2007) Removal of anionic reactive dyes from water using anion exchange membranes as adsorbers. Water Res 41:1491-1500

Liu Y-W, Guan M-X, Feng L, Deng S-L, Bao J-F, Xie S-Y, Chen Z, Huang R-B, Zheng L-S (2013) Facile and straightforward synthesis of superparamagnetic reduced graphene oxide- $\mathrm{Fe}_{3} \mathrm{O}_{4}$ hybrid composite by a solvothermal reaction. Nanotechnology 24:25604-25614

Monash P, Pugazhenthi G (2009) Adsorption of crystal violet dye from aqueous solution using mesoporous materials synthesized at room temperature. Adsorption 15:390-405

Muruganandham M, Swaminathan $\mathrm{M}(2006) \mathrm{TiO}_{2}-\mathrm{UV}$ photocatalytic oxidation of Reactive Yellow 14: effect of operational parameters. J Hazard Mater 135:78-86

Namvari M, Namazi $\mathrm{H}$ (2014a) Clicking graphene oxide and $\mathrm{Fe}_{3} \mathrm{O}_{4}$ nanoparticles together: an efficient adsorbent to remove dyes from aqueous solutions. Int J Environm Sci Technol 11:1527-1536

Namvari M, Namazi H (2014b) Sweet graphene I: fabrication of water-soluble graphene nanosheets by covalently attaching alkyne-terminated saccharides onto azide-modified graphene oxide by "click" chemistry. Carbohyd Res 396:1-8

Namvari M, Namazi H (2014c) Synthesis of magnetic citric acidfunctionalized graphene oxide and its application in the removal of methylene blue from contaminated water. Polym Int 63:1881-1888

Namvari M, Namazi H (2015) Preparation of efficient magnetic biosorbents by clicking carbohydrates onto graphene oxide. J Mater Sci 50:5348-5361

Novoselov KS, Geim AK, Morozov SV, Jiang D, Zhang Y, Dubonos SV, Grigorieva IV, Firsov AA (2004) Electric field effect in atomically thin carbon films. Science 306:666-669

Qu S, Huang F, Yu SN, Chen G, Kong JL (2008) Magnetic removal of dyes from aqueous solution using multi-walled carbon nanotubes filled with $\mathrm{Fe}_{2} \mathrm{O}_{3}$ particles. J Hazard Mater 160:643-647

Ramesha GK, Kumara AV, Muralidhara HB, Sampath S (2011) Graphene and graphene oxide as effective adsorbents toward anionic and cationic dyes. J Colloid Interface Sci 361:270-277

Shen JF, Hu YZ, Shi M, Li N, Ma HW, Ye MX (2010) One step synthesis of graphene oxide-magnetic nanoparticle composite. J Phys Chem C 114:1498-1503

Shin S, Jang J (2007) Thiol containing polymer encapsulated magnetic nanoparticles as reusable and efficiently separable adsorbent for heavy metal ions. Chem Commun 41:4230-4232

Sun H, Cao L, Lu L (2011) Magnetite/reduced graphene oxide nanocomposites: one step solvothermal synthesis and use as a novel platform for removal of dye pollutants. Nano Res 4:550-562

Thuy-Duong NP, Hung VP, Kim EJ, Oh ES, Hur SH, Chung JS (2012) Reduced graphene oxide-titanate hybrids: morphologic evolution by alkali-solvothermal treatment and applications in water purification. Appl Surf Sci 258:4551-4557

Wang C, Feng C, Gao Y, Ma X, Wu Q, Wang Z (2011) Preparation of a graphene-based magnetic nanocomposite for the removal of an organic dye from aqueous solution. Chem Eng J 173:92-97

Xie G, Xi P, Liu H, Chen F, Huang L, Shi Y, Hou F, Zeng Z, Shao C, Wang J (2012) A facile chemical method to produce superparamagnetic grapheme oxide- $\mathrm{Fe}_{3} \mathrm{O}_{4}$ hybrid composite and its application in the removal of dyes from aqueous solution. J Mater Chem 22:1033-1039

Yang X, Zhang X, Ma Y, Huang Y, Wang Y, Chen Y (2009) Superparamagnetic graphene oxide- $\mathrm{Fe}_{3} \mathrm{O}_{4}$ nanoparticles hybrid for controlled targeted drug carriers. J Mater Chem 19:2710-2714

Yang S-T, Chen S, Chang Y, Cao A, Liu Y, Wang H (2011) Removal of methylene blue from aqueous solution by graphene oxide. J Colloid Interface Sci 359:24-29

Yao Y, Miao S, Liu S, Ma LP, Sun H, Wang S (2012) Synthesis, characterization, and adsorption properties of magnetic $\mathrm{Fe}_{3} \mathrm{O}_{4} @$ graphene nanocomposite. Chem Eng J 184:326-332

Zhan Y, Yang X, Meng F, Wei J, Zhao R, Liu X (2011) Controllable synthesis, magnetism and solubility enhancement of graphene nanosheets/magnetite hybrid material by covalent bonding. J Colloid Interface Sci 363:98-104

Zhang X, Yang X, Ma Y, Huang Y, Chen Y (2010) Coordination of graphene oxide with $\mathrm{Fe}_{3} \mathrm{O}_{4}$ nanoparticles and its enhanced optical limiting property. J Nanosci Nanotechnol 10:2984-2987

Zhao W, Wu Z, Wang D (2006) Ozone direct oxidation kinetics of Cationic Red X-GRL in aqueous solution. J Hazard Mater 137:1859-1865

Zhu AP, Yuan LH, Liao TQ (2008) Suspension of $\mathrm{Fe}_{3} \mathrm{O}_{4}$ nanoparticles stabilized by chitosan and o-carboxymethyl chitosan. Int $\mathbf{J}$ Pharm 350:361-368

Zhu Y, Murali S, Cai W, Li X, Suk JW, Potts JR, Ruoff RS (2010) Graphene and graphene oxide: synthesis, properties, and applications. Adv Mater 22:3906-3924

Zhu JH, Wei SY, Haldolaarachchige N, Young DP, Guo ZH (2011) Electromagnetic field shielding polyurethane nanocomposites reinforced with core-shell Fe-silica nanoparticles. J Phys Chem C 115:15304-15310 